\title{
Study on the development strategy of rural sports in the construction of New Countryside
}

\author{
Shumei $\mathrm{Yi}^{1 \mathrm{a}}$ Ying $\mathrm{Li}^{2 \mathrm{~b}}$ \\ 1,2 Pingxiang University, Jiangxi 337055, China \\ a340466055@qq.com, b359020645@qq.com
}

\begin{abstract}
Key words: new countryside; development; rural sports
\end{abstract}
\begin{abstract}
Sports has significant position and role in the new rural construction, play an important role to enrich farmers' spiritual and cultural life and realize harmonious society. Therefore, to correctly understand and play the advantages of rural sports in the new rural construction, further proposes the establishment of rural sports development of new ideas.
\end{abstract}

The construction of new socialist countryside is a major historic task in China's modernization process. As an important part of rural culture, The rural sports is facing a rare historical opportunity and challenge. In the construction and the harmonious society to re-examine the new rural sports development issues of new rural construction, seriously think about how to enhance the physical quality of farmers, how to make the largest rural sports resources, how to play a greater role in sports, is the most important task for the sports workers. In the new historical conditions, a clear understanding and accurate grasp of the situation of rural sports, and on this basis to explore countermeasures of rural sports construction, it has great practical significance.

\section{Sports in the construction of new rural status and role}

\subsection{Sports is an important thrust to promote the development of new rural economy}

Sports as a public sports investment, investment benefit mainly implicitly slow and sustained release, significant social benefits, promote the rural sports of economy is mainly reflected in order to improve the physical quality of workers, reduce the incidence rate of rural residents, improve the quality of life. To reduce the incidence of rural residents, improve the quality of life. From this point of view, between the development of rural sports and rural economic development has the intrinsic fit.

\subsection{Sports is an important carrier of the construction of spiritual civilization in the new rural areas \\ Sports as a social culture, is to build the human spirit and the sublimation of human thought in a highly civilized and noble morality, purify the human mind and inspire people's spirit, improve the quality of people and temper the will of the people. In the process of new rural construction, to prevent and improve the rural areas, peasants face it remains the same. Therefore, strengthening the construction of sports culture in the new rural construction, the farmers of morality, values, have an important impact on interpersonal relationship, to change the backward rural areas not healthy living concept, optimize the social environment, will play an important role in promoting the spiritual civilization construction in the new rural development.}

\subsection{Physical education is an important way to improve the quality of the "new farmers"}

The determination results released in 1998 China adults constitution shows that farmers' body shape, quality, function and so on most of the indicators below the scientific and technical personnel, administrative personnel, workers and other parts of the population, the farmer is still high incidence of cancer, cardiovascular diseases and infectious diseases, the physical quality of farmers is not high and the high incidence rate is an important factor restricting the rural the development of economy.

The farmer is the main body of building a new countryside, farmers' health quality directly determines the pace of building new countryside. To improve farmers' health quality is an important 
part of constructing harmonious society, and is also an important factor affecting China's economic and social sustainable development. Rural sports not only contribute to the development of farmers' health, reasonable way of life, and to create a civilized and harmonious social environment. To comprehensively promote the construction of new countryside sports culture, set up the healthy life concept, strengthening folk custom, folk construction is an important way.

\subsection{Sports stimulating new rural sports consumption, promote industrial development}

By the geographical environment, the influence factors of traditional ideas and the income of the rural population, most of the sports consumption consciousness, the rural sports market in China is still in the primary stage. With the new rural sports construction, rural sports activities, the transformation of China's peasants' sports concept radically and sports. The concept of change and improve people's income level, will greatly promote the new rural sports consumption market development. Therefore, the expansion of sports consumption, will promote the development of new rural sports industry and related industries.

\section{New challenges in the development of rural sports in the construction of New Countryside}

\subsection{Unbalanced development of rural sports}

The imbalance of China's economic development, regional differences also created the imbalance of the development of rural sports. At present, the farmer sports values from the beginning of "labor substitution" to "healthy entertainment". However, in the western rural areas of our country and some underdeveloped area, due to the economic development lags behind, rural sports basically in the state. No one shows any interest in some areas, farmers have fitness needs, but the objective conditions can not meet the basic needs of hard to get up; some areas, poor farmers' physical health status, but not aware of the exercise needs.

\subsection{The increasing mobility of the population}

But with a large number of rural labor transfer, many educated, knowledgeable in the full vigour of life, farmers in the outflow of the "empty nest" the trend is obvious. More and more "empty nest" the old man, left-behind children constitute a special group of people in the growing and a common social phenomenon. Due to the lack of love, affection hunger left-behind children, introverted and withdrawn. Easily influenced by some bad behavior. Many left-behind children without school, truancy, dropouts have occurred. The emergence of these phenomena, not only make the new rural construction is facing severe challenges, also make the new rural sports organization work is facing new problems.

\subsection{Tax reform brings new impact}

A direct consequence of the tax reform led to the development of rural sports is that public funding gap larger, which including sports public funds decline, makes the number of sports funds is difficult, especially in poor and backward areas, will be more difficult situation.

\section{Development Countermeasures of rural sports}

\subsection{Focus on farmers, based on villages}

The new rural construction can not be ignored the role of rural sports. To solve the problem of peasant sports, the relationship between social sports situation, is also related to the overall situation of the new rural construction. Therefore, we need to establish a "farmer oriented" thought, with comprehensive, coordinated, the scientific concept of development to farmers' physical and mental health put on the schedule, to achieve the ultimate concern of farmers.

\subsection{Improve the sports facilities maintenance system}

The development of new rural sports should be based on the sports infrastructure construction as the breakthrough point, combined with the actual situation, the development of rural social economy will integrate resources, sports facilities and local rural infrastructure plan. The construction of sports facilities should be included in the local government work plan, the formation of government support, relying on the society, should open up the market and all the people involved in the operation mechanism, according to local conditions, make full use of existing public 
facilities in rural areas, and as far as possible to play sports fitness, culture, etc.. At the same time gathering function of sports facilities and sports organizations closely combined activities of construction, for the sports venue into a fixed mass morning or evening.

\subsection{Establish the system of farmers' physical fitness monitoring}

Establish and improve the national physique monitoring system, can provide a scientific basis for farmers to participate in physical exercise. The district sports administrative departments to send physical inspection car, to the countryside for determination of farmers free fitness. At the same time should organize relevant experts held a sports fitness and life science lectures, the obligation to carry out fitness guidance and health advisory services. Every year there are plans to target the rural masses according to different ages and areas of scientific sampling, detection of farmers', do the national physique test in the implementation of work in the rural areas.

\subsection{Give full play to the advantages of rural sports}

The leisure life is monotonous, less interference factors, attractive variety of sports activities on farmers may be larger than the urban residents. Sports is dependent on its highly competitive, changes to attract the audience and participants, the essential characteristics of these sports is $\mathrm{Fu}$ Henong people interest in taste and cultural value. A considerable proportion of farmers the population, such as the elderly, women rarely participate in productive labor, their leisure time more than urban residents. Should fully show the sports charm, guide the leisure orientation of them.

\subsection{Give full play to the role of rural grassroots organizations}

The operation of the most basic unit of rural sports is a statutory administrative village, the village committee jurisdiction of the community, it is built for the premise. The main functions of the villagers' committee and rural construction work of village committee is highly consistent. It as the villagers' self management, self education, self serving grassroots autonomous organizations in itself responsible for convenience services, safeguard the legitimate rights and interests of the villagers, to carry out the construction of spiritual civilization in rural area for residents, villagers public affairs and public welfare undertakings and other rural community construction tasks.

\subsection{Integration of sports resources in rural schools}

In recent years, with the help of software and hardware, power of primary school, let rural school resources play an important role in the development of peasants' sports activities, there is a shortcut to quickly develop the rural sports. In the very lack of rural sports resources, school sports and rural sports two-way junction with each other is not only human, effective use of resources. So many problems in the development of rural sports can be solved, but also for sports culture, the dissemination of knowledge also has a very important significance.

\subsection{Strengthen the sports management of migrant workers and migrant workers}

As a huge and very special group, sports participation and their physical and mental health of migrant workers to fully implement the national fitness program outline, to improve the physical quality of the whole nation, has the important significance of constructing the harmonious well-off society. The local government should according to the local economy and education, the scale and level of health work development. The development of sports of migrant workers into the overall economic and social development of rural culture and education in the planning of the development planning of Migrant Workers Sports formulation meets the actual situation. At the same time, according to the rural population to the city of migrant workers continues to increase, the flow characteristics of population, but also pay attention to sports management problems of migrant workers.

\section{Acknowledgments:}

Draft date: 2016-10-1

Fund project: jiangxi province sports bureau scientific research subject 《The Present situation and Countermeasures of rural sports development in the new rural construction》, number: 2016036 


\section{Reference}

[1] Xiao-Hong Zhao. Construction of new rural sports culture[J]. Journal of Hebei Normal University of Science and Technology, 2007 (1)

[2].Fa- Qiang Zhang.prosperity of rural sports, for the construction of rural social contribution of Yi Xin Bian [Z]. speech at the national working conference of the farmers association, 1999:26

[3] Hui-Qiong Shi. Nanning 130 thousand rural empty nest family survey: parents a mothering [N]. farmer daily, 2007-01-26 (4)

[4]Xin Huang. Thinking on the development of rural sports in the new rural construction[J]. Journal of Shanghai Institute of Physical Education, 2006 (6)

[5] Hong Yuan. Discussion on the effective way of rural sports in China[J]. Journal of East China University of sport, 2005 (4)

[6] Hui-Zeng Li. China's high Edmonton area small town sports present situation and development of model [J]. Journal of Shanghai Institute of Physical Education, 2005 (5) 